\title{
Usable Interface Design for Everyone
}

Carlos de Castro Lozano ${ }^{1}$, Enrique García Salcines ${ }^{1}$, Beatriz Sainz de Abajo $^{2}$, F. Javier Burón Fernández ${ }^{1}$, José Miguel Ramírez ${ }^{1}$, José Gabriel Zato Recellado ${ }^{3}$, Rafael Sanchez Montoya ${ }^{4}$, John Bell ${ }^{1}$, Francisco Alcantud Marin ${ }^{5}$

${ }^{1}$ EATCO Research Group. University of Cordoba.

Edificio Leonardo da Vinci. Campus de Rabanales. 14071 Córdoba, Spain. \{ma1caloc, egsalcines, jburon\}@uco.es; jmiguelramirez@gmail.com; jbellworks@gmail.com;

${ }^{2}$ Telecommunications Technical School (ETSIT). University of Valladolid. Campus Miguel Delibes. Paseo de Belén no 15, 47011 Valladolid, Spain. beasai@tel.uva.es;

${ }^{3}$ Telecommunications Politechnical School (EUP). University of Madrid. C.E.U. Department of Applied Intelligent Systems, Madrid, Spain. jzato@eui.upm.es

${ }^{4}$ EUEJE Campus Bahia de Algeciras University of Cadiz, rsanchez@arrakis.es

${ }^{5}$ ACCESS Research Unit. University of Valencia. Francisco.Alcantud@uv.es

\begin{abstract}
When designing "interfaces for everyone" for interactive systems, it is important to consider factors such as cost, the intended market, the state of the environment, etc. User interfaces are fundamental for the developmental process in any application, and its design must be contemplated from the start. Of the distinct parts of a system (hardware and software), it is the interface that permits the user access to computer resources. The seven principles of "Universal Design" or "Design for Everyone" focus on a universal usable design, but at the same time acknowledge the influences of internal and external factors. Structural changes in social and health services could provide an increase in the well-being of a country's citizens through the use of self-care programming and proactive management/prevention of disease. Automated home platforms can act as an accessibility instrument which permits users to avoid, compensate, mitigate, or neutralize the deficiencies and dependencies caused by living alone.
\end{abstract}

Keywords: Person-to-computer interaction; interface; flexible; dependence; usability.

\section{Introduction}

To successfully, coherently and cognitively focus on person-to-computer interaction, as shown in the following figure, one must understand that both humans and computers process information. If the basic mechanisms which underly human 
cognition and computer systems are the same, it is possible to use the same methods and concepts to analyze both. From this information, one can compose a general theory which explains the functionality of high level systems devised by computers and people [1]. Numerous studies have been made about this topic [2-4].



Fig. 1. person-to-computer interaction layout (modified from Preece et al. [5])

Interfaces which are more realistic and are adapted to user characteristics have lead to the creation of new applications. Virtual reality systems serve as an example of this, where the user interface permits an interactive exploration in such a way that the perception of a realistic environment is amplified. There are sophisticated systems which heighten the sensation of immersion: virtual reality, augmented reality, glasses, sensory gloves, curved screens, etc. Virtual scenes can be made interactive, with virtual images that are developed through special processes and accompanied by nonvisual elements such as tactile and audio systems. The purpose of these elements is to convince the user to integrate into a synthetic but real environment.

The success of interactive systems is characterized by an emphasis on user participation. User interfaces are fundamental for the developmental process in any application, and its design must be contemplated from the start. Of the distinct parts of a system (hardware and software), it is the interface that permits the user access to computer resources. Thimbleby [6] suggests that the interface determines a user's perception and impression of an application. Users are not interested in the internal structures of an application, only in how to use them. The seven principles of "Universal Design" or "Design for Everyone" focus on a universal usable design, but 
at the same time acknowledge the influences of internal and external factors. When designing "interfaces for everyone" for interactive systems, it is important to consider aspects such as cost, the intended market, the state of the environment, etc. Preece establishes the following directives for creating an interface design that is accessible and adaptable for everyone [7]:

- Know who is going to use the interface.

- Reduce the cognitive load.

- $\quad$ Error engineering: take measures to avoid possible user errors.

- Maintain clarity and consistency. Help create and maintain system mental models for users.

- Understand the (psychological, ergonomic, organization, and social) factors that determine how people work and use computers. By implementing this knowledge in tool and technical development, designers create ideal systems for activities - as well as efficient, cogent, and effective interaction on a user and group level.

"An interactive system design should satisfy the demands of those users who are going to use it." The computer is a tool which performs a determined job or activity. For a computer to be a good tool, it must be adequate, comfortable, and efficient in carrying out a task. A good design is achieved through a thorough analysis of the contexts where these assignments occur [8]. For this, user characteristics, activities, and environments must be analyzed. All of these factors define which system design requirements should be met.

A fundamental characteristic in interactive system development - with universal user interfaces - is the constant evaluation of its usability among people with disabilities. Through this method, it is fairly simple to try out different technical interface elements or components while developing a final prototype, and make modifications at each stage. For interface designers and Human Computer Interaction (HCI) researchers, the need for usability evaluation during the development process is evident [7, 9-12].

"Usability" can be defined as the level at which a product adapts to user needs, and can be used to reach objectives with effectivity, efficiency, and satisfaction [13]. This concept of "usability," because of its focus on user satisfaction, can be implemented to establish user interface evaluation standards. As it is difficult to measure usability directly, the best way to assess it is through indirect means or by the attributes which make up the concept of "usability." According to Alcantud usability is the inclusion, on a large or small scale, of [14]:

- Effectivity: any interface should have clear and reachable objectives.

- Efficiency: this characteristic depends on the user's ability and the capabilities of the software. To analyze this correctly, one must perform a study on the different types of users.

- Learnability: the system has to be easy to learn so that a user can rapidly start working with it.

- Memorability: the different aspects and functionalities of the system must be memorable to the point where a user has no problems using it after extended periods of time.

- Retainability: control over the system and user errors. 
- Satisfaction: the subjective state where a user has successfully performed a task without difficulties.

An application cannot reach a user without evaluating every interface component first, and without evidence that the application produces significantly better results in comparison to the existing conventional systems.

\section{Usability laboratory}

Traditional scientific experimentation is performed in a controlled environment, resulting in maximum accuracy. Unfortunately, on occasion, the results of a controlled experiment can conflict with those of reality.

In the case of interface prototype evaluations, users must work with the computer or device in the exact setting for which the interface is intended. Usability laboratories are a place where these tests can take place [15]. A usability laboratory is a physical space which emulates the habitual work environment. Among the instruments in the laboratory should be an automatic video or semi-automatic video recording system to register interactions and responses for posterior evaluation. There should be one-way mirrors (to avoid observer detection), audio recording systems, and screen-action registering systems as well. Nielsen [16] performed a study on a total of thirty laboratories and came to the conclusion that: the majority of the laboratories date from 1989, although there are some which are older. $92 \%$ of these laboratories have one-direction mirrors, only $46 \%$ have direct screen recording systems, and all have video camera recording systems with a medium of 2 cameras per laboratory.

The ACCESO group from the University of Valencia developed a laboratory through the help of the "HAMTutor: Instruction Design for tele-education and author tools with intelligent tutors for the disabled" project, financed by FEDER funds (European Funds for Regional Development), and with the collaboration of the EATCO group at the University of Cordoba. This laboratory provided interaction observation for: individual and group interaction (up to three people at a time); for standard and specific system interaction; for interaction with the disabled; and for the interface design of the iFreeTablet ${ }^{\circledR}$.

The objective was to establish a usability evaluation system for computer interfaces and systems, to assess usability during software design processes, and to define which adaptation/accessibility systems people with disabilities can use in order to eliminate any barriers between them and computer access. For this motive, the laboratory had to be very flexible and adapt to a series of different situations.

Currently, data mining is being developed with an emphasis on genetic and evolutionary fields. Nonetheless, it is already being used to evaluate learning activities on the internet, and create assessable models based on user information. By analyzing this information one can determine associations between visited pages, analyze visited page sequences, and asses user types/classes and their preferences.

Parts of these evaluations are performed via nervous system measurements. A person under stress undergoes a series of changes in their nervous system which can be observed with the appropriate tools. When a person is relaxed, the fluctuations in the nervous system achieve baseline values [17]. 

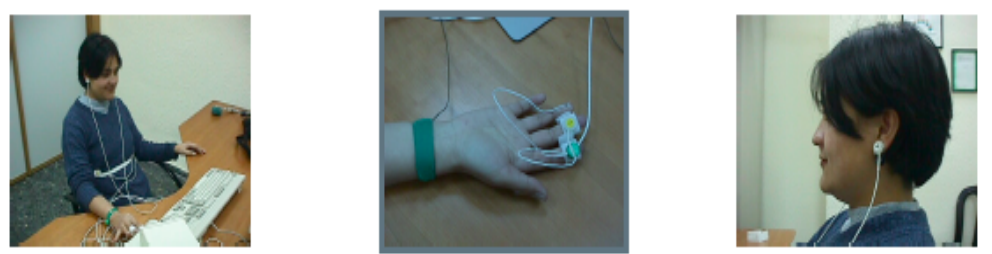

Fig. 3. Different electromyograph and polygraph electrode positions.

The most frequently used devices to observe changes in the nervous system are: the electromyograph (EMG) which measures potential electric currents and muscle activity in muscular fiber; the electroencephalogram (EEG) which registers brain waves; the electrodermograph which measures the capacity of skin galvanic reactions (GSR) and shows modifications in its conductivity [18]; the thermograph (TP) which measures changes in skin temperature due to external vasoconstriction; and the pneumograph which observes thorax cavity expansion and consequentially the volume and frequency of respiration.

The different measurements tend to correlate when the subject is placed in a stressful or emotional situation - although there are external factors to consider [19]. When interpreting the results, one should keep in mind that the mechanisms which control internal temperature aren't necessarily related to nervous system activities that control skin temperature. There are other influential factors, such as blood viscosity, the temperature of the surrounding environment, or biochemical factors such as the presence of lactic acid, carbon dioxide, nicotine, or alcohol in the blood. Psychological factors, like emotional tension, anxiety, and stimulation can influence results as well. The nervous system's response to these different stimulants provoke changes in cardiac volume, arterial pressure, and external vasomotor activity [20].

\section{Computer interaction devices and systems for people in situations of dependency}

3.1 Natural language recognition and synthesis (voice, writing, line drawing, signals, and gestures)

The current use of Aid Technology (TA) is expanding the field of useful, interactive, and multi-sensorial devices for the development of communication and language abilities. Users who experience difficulties communicating find this technology to be psychologically comprehensible and flexible, and are able to overcome communication impediments fundamentally for two reasons: 
- TA provides support for all symbolic systems (pictographs, morse, braille, etc). People with communication disabilities normally feel limited by traditional systems.

- Characters and images in Aid Technology are not static information symbols, but rather are the final representations of products and processes. These "representations" provide a more fluid communication experience.

The ALDICT project (Access for Persons with Intellectual Disability to Information and Communication), which produced the software "Writing with Symbols 2000," made web information sharing for people with communication and learning difficulties easier. The project developed a friendly interface based on the PCS, Rebus, and PIC symbol systems - allowing a wide range of communication techniques possible. This interface permitted the user to express both basic and advanced cognitive requirements, and provided simultaneous translation services between local and online users. This experience was evaluated very positively by more than 130 selected users from French, German, Portugal, and United Kingdom organizations (Inclusion for Europe, 2001). The results of these assessments confirm that the human eye is capable of simultaneously understanding diverse forms of information. As a result the creation of an effective graphic language with semantic fields that correspond to visible physical realities, and that encourage learning and communication, is a possibility. The use of microphones, which convert the speech acoustic parameters into interactive graphics, are reinforced by digitalized auditive synchronized repetitions. These visual animated effects permit speech therapists to motivate their patients and define parameters with notable clarity.

Interaction with a symbolic system is flexible and multi-sensorial. In only a few years, microelectronic development has increasingly prompted the production of devices which can connect to the computer. Currently, apart from the senses of smell and taste, it is possible to interact with all human senses.

Users which suffer from disorders can find new technologies which provide communication aids and alternatives in order to improve linguistic aptitudes. Among the newly developed technologies which offer interesting possibilities are wearable computers, and tablet PCs. Erwine Middle School (Ohio, USA) uses these devices and has achieved excellent results among people with autism and cerebral paralysis. As they are easy to use and transport, these devices become elements which a person can easily incorporate into their lives - much like glasses or a cane.

The project "Multisensory Environments: the use of interactive technology," from the London Institute of Education and University of Birmingham, demonstrates how multi-sensorial simulation (SME) can be considered as a way to perfect multimedia resources. Sounds, smells, lights, tactile surfaces, and system technology provide means to which students with severe communication and learning difficulties can improve motor and perceptive activities. The use of SME technologies can improve their integral and harmonic development [21].

The systems that do not have these kinds of aids have the advantage of being more dynamic, autonomous, economic, and easier to use - as communication is performed using the body. At the same time, however, they are more demanding in terms of cognitive aptitude and in short term memory, and do not last permanently on the market. 


\subsection{Learning through augmentative communication systems and speech accessories.}

People with auditive deficiencies and deafness have difficulties coping in a society that uses the spoken and written word as the main communication medium. With this context in mind, Communication and Information Technologies (TIC) provide an opportunity which can eliminate communication difficulties, be integrated into the daily routine, and provide better chances for employment, education, and social welfare.

The most promising software for people who suffer from deafness or auditive deficiency helps users by reeducating them in speech (Speechviewer, Metavox, Visha, etc.), providing augmentative systems and communication alternatives (Sistema Bimodal'2000, Signos, La Palabra Completada, SIMICOLE, etc.), and teaching linguistic strategies.

Fluent Animated Speech, which was developed by the company Sensory (www.sensoryinc.com), is a computer application which teaches speech to deaf children. Its engaging design attracts the child's attention with a 3D virtual doll that vocalizes words in a clear and perceptible manner. Through this system, a child can begin to recognize mouth movement and the facial expressions of its new "companion." Dolls can be customized by picking distinct physical characteristics. This product has been very positively rated at the North American "Tucker Maxon school for deaf children."

Another group of investigators who are experts in virtual reality (three-dimensional computer images) - from the British business Televisual - are working on sign language interpretation for computers. This system allows the deaf to communicate with others without the presence of an interpreter. The base of this system is a combination of software which recognizes speech and the movements of an interpreter archived through the use of sensors placed on the face and hands of a specialist.

\subsection{Information sharing and supported knowledge in a virtual environment}

Lower digital camera prices and increased internet connection quality/velocity is converting virtual environments (videoconferences, virtual reality, etc.) into something more habitual. Many disabled citizens can benefit from these inventions: deaf people who communicate orally or with sign language, people with intellectual deficiencies who can use visual aids from a compute screen, and generally any professional who has problems commuting.

By using a PDA (Personal Digital Assistant), users - that need to use wheelchairs or have difficulties gaining access to a computer - can easily verify and obtain data, receive emails, send faxes, make telephone calls, or connect to their computer. These tasks can also be performed through devices such as the iFreeTablet. 


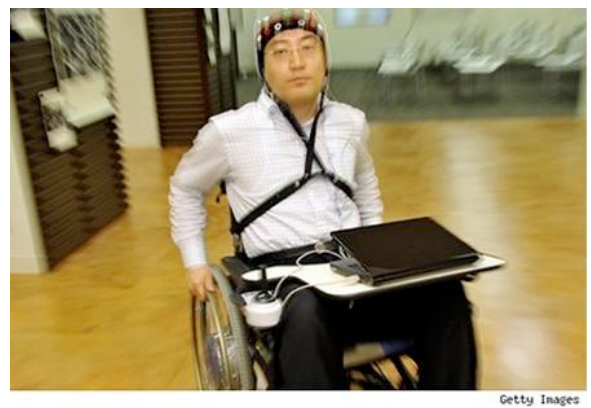

Fig. 4. Communication systems with physical aids.

3.4 Language and communication improvement with the help of software and electronic devices

Clearly, people who suffer from blindness or visual deficiency find interacting with a computer difficult, as they cannot perceive multiple visual cues that a computer screen or printer provides. While these users can manipulate a keyboard to quickly introduce data (in the case of pigmentary retinosis - simple, high contrast, adhesive tags ease keyboard character identification), screen information interpretation and manipulation is not easy.

"Portable-braille" is becoming more common, and permits users to introduce data in computers through the use of the 8 point braille system (which includes the highest number of standard braille characters). This device incorporates a voice synthesizer that reproduces information that is being written in any given moment, or information that is stored. Connection ports for communication with other devices are also included.

How information is presented on the screen is important. The adaptive technology for people who have visual deficiencies is different, and in some cases auxiliary. These technologies/devices aid users through:

SIGHT - the purpose of screen magnifiers, which act as magnifying glasses, is to make information larger. Accessibility properties offer users the chance to change contrast ratios, color combinations, mouse pointers, etc. The iFreeTablet is a good example of a device that enhances sight, as it uses the Guadalinex system's magnifying glass.

SOUND - voice synthesis systems read the texts that appear on computer monitors out loud. This is possible through the activation of a reader program or screen revisor (Orca, Jaws, Hal, Simple Talker, Winvision, etc). In the last few years, advances have been outstanding in terms of quality and potential. There are even "speaking" web navigators in development such as Festival, IBM Home Page, Reader, Simply Web, Connect Outloud Browser, etc.

TOUCH - braille lines allow blind people to read information that appears on computer screens. This is possible through the use of a device with a wide surface which reproduces braille in relief via electromechanical cells. Configuration menus and audible aids ease braille/user adaptation. 




Fig. 5. Braille keyboard

\subsection{Learning how to use Augmentative and Alternative Communication Systems} with multimedia aids

Learning how to use Augmentative and Alternative Communication Systems (SCAA), with pictograph system supports, can serve as a benefit for people who have difficulties speaking, reading, or writing. The most common causes for these problems are intellectual, motor, or sensorial disabilities that serve as obstacles for speech and writing ability development. Traumas or sickness can also interrupt growth, and in turn cause these problems. Augmentative and Alternative Communication Systems are used generally by people with cerebral paralysis, autistic traits, blindness, deafness, and users which need non-vocal code communication.

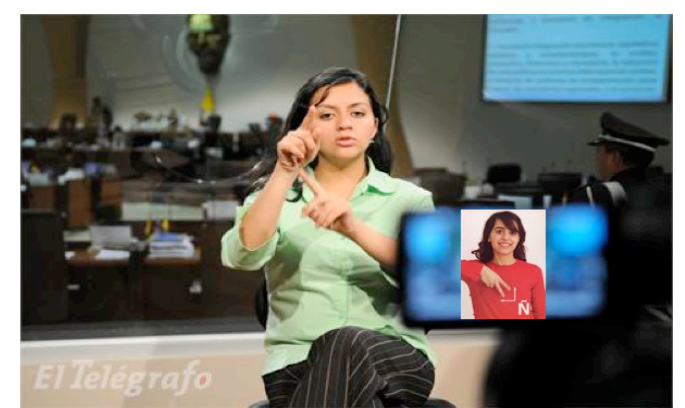

Fig. 6. Sign language through video conference

\section{Future tendencies in new interface development}

For as long as computers have existed, there have been barriers that have impeded human interaction. Until now, the most common devices that have provided access to the computer have been the mouse and keyboard. Although voice interaction will have a place in computer development, it is unlikely that it will become the preferred 
form. Rather, a combination of various systems (visual, position, gesture, voice recognition, touch, etc.) is the most probable solution to the evolution of the traditional person-to-computer interface. Of the systems, the ubiquitous multimodal systems and the adaptive and intelligent hypermedia systems stand out among the future tendencies in interface development.

\subsection{Ubiquitous multimodal systems}

According to Dürsteler, "human and computer interfaces still suffer from many shortcomings. The multimodal systems, which use multibiometric elements, multimodal interfaces and multisensorial systems are beginning to resolve many of these [insufficiencies]". As a result of human-computer problems, a new generation of multimodal systems is in development to find solutions. This new generation is based on: multibiometric systems that combine diverse biometric techniques which reduce error margins; multimodal interfaces that convert objects in a given environment into digital interaction elements; and multisensor systems that support the various synergetic multimodal and multibiometric combinations [22].

A simple example of a bimodal application is NISChart, which was developed by Natural Interaction Systems. This system permits doctors to combine voice recognition with normal writing on paper using the digital pen Anoto, which acts as a normal pen and detects movement at the same time. These gestures are captured thanks to a series of special printed marks on the paper, so any movement is communicated to the computer.

The development of current multimodal interfaces should evolve to the point where a user can interact with a system (via telephone, computer, television, electronic agendas, etc.) in a comfortable manner which is adaptable, robust, and error tolerant. By incorporating different modes of communication into an interface, the barriers which deny people in situations of dependency access to technology shall be removed. Voice interfaces, for example, are easier to use and require/demand less attention from a normal user. Using this reasoning, one can initiate a line of investigation which has the potential to provide people who have disabilities with access to this type of technology. This norm was applied during the design of SieSta, the operating system of the iFreeTablet, in such a way that the functions, organization, and concepts of the system follow a certain philosophy. For this particular system, there are six numerated pushable zones that are associated with six colors. The end result is that any given scenario is simplified to the point where there are no more than six actions a user can perform, which can be activated through touch, or through voice, gestures, or movement.

The development of computers that can think and act like people has been studied for years. These investigations have lead to the creation of machines that are sensitive to emotions thanks to the participation of experts from psychological, communicative, image process, computer science, philological, sign process, computer graphic, and artificial intelligence fields (amongst others). Humaine is a project that hopes to achieve exactly this, with the help of 160 investigators from 27 European institutions. This 4 year project - with a 10 million euro budget - is focused on multimodal interfaces that allow computers to understand the user's habits and needs, and respond 
adequately to them. Professor and project coordinator Roddy Cowie, from the psychological department at Queen's University, remarks that: "The computers that respond to human emotions seem like science fiction today, but they will exist. At this moment computers are limited to the keyboard and screen. If we could talk to them through a microphone, the difference would be enormous. But emotions are part of speech, and experience shows that the majority of people dislike talking to a machine. For this reason, if we were to make more intuitive, expressive, and easy to use computers there would be more people who would take advantage of them."

Natural spoken language or written investigations for the blind and deaf play a significant role in multimodal interface development. These investigations are important (as well) for the creation of computerized dialogue systems which model natural language communication mechanisms that imitate human behavior. Since 1984, the Spanish Society for Natural Language Processing (SEPLN) has been a nonprofit association formed by a variety of partners and institutions with the hopes of encouraging both national and international teaching, investigation, and development activities which focus on natural language processing.

Indisys (Intelligent Dialogue Systems) is a "spin-off" of the Julieta computational linguistic investigation group from the University of Seville. This group is dedicated to the creation of intelligent dialogue systems, or natural language voice interfaces which ease communication between a human user and a computer system. The idea is to provide the system with the ability to speak and understand natural/spoken languages without the user having to train previously or memorize commands. Indisys initially chose to work with two fields: automated environments, and telephonic autoservice. In the first case the user is provided with a virtual butler that can be accessed from any interior part of the house, via telephone or internet, and which controls all of the automated system devices (lights, heat, alarms, doors, blinds, etc.). In the second case the user can access a virtual telephone operator without having to deal with a series of predetermined menus. In both cases the system uses a dialogue manager, LOCUAZ, that provides a conversation-intelligence which follows and interprets the context of the dialogue in order to decide what to do: ask for more information, answer a question, perform a task, etc.

The quantity of applications which could offer this technology are unimaginable. In determined fields it would be easy to create systems which teach users in order to encourage the use of certain materials. One of the more interesting possibilities is an application which provides the disabled, the elderly, and those in situations of dependency with the ability to dominate their environment in a natural way, without having to train and with the added plus of a system that can monitor their needs.

Third and fourth generation telephones ( $3 \mathrm{G}$ and $4 \mathrm{G}$ ) provide advantages in relation to interface analysis. Apart from being telephones, these devices serve as videocameras, personal computers, digitalized music players, and remote controls. For the construction of Voice-based User Interfaces there is currently a web standard called VoiceXML, which was conceived for human-computer dialogue and permits the development of services in response of interactive voice (IVR). If VoiceXML were paired with the variety of services that modern telephones offer, one could develop a universal remote control with an integrated voice navigator. This remote control would consist of a VoiceXML homepage and a list of URLS linked to any 
available devices. Through use of the remote control, VoiceXML would interpret menu choices, and retrieve the menu options of a chosen device.

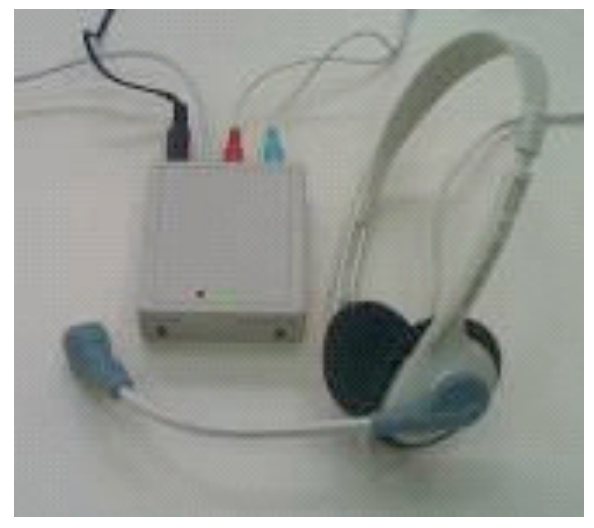

Fig. 7 Mouse system emulator with voice recognition

Another future tendency has to do with interface design on a molecular level, which is to say the use of nanotechnology. Nanotechnology applications are becoming a reality, especially in the optoelectronic industry. Highly sensitive magnetic and compact-disc laser readers are the first devices with nanostructure materials to reach the market. Industrial and social impact from nanotechnology will go even farther in the future.

The most recent advances in ubiquitous computation have brought about the concept of "environmental intelligence" and new intelligent interaction possibilities between people and machines. In terms of practicality, environmental intelligence consists in the creation of a series of objects which are used daily and whose interactive qualities are "smooth" and non-intrusive. The current systems based on environmental intelligence provide intuitive/intelligent interfaces for: furniture, clothing, vehicles, roads, and even paintings and cloths. All of these objects are capable of detecting human presence, personalities and needs - and respond in discontinuous, discreet, and frequently invisible ways.

Ubiquity, transparency, and intelligence are the three basic environmental intelligence properties. Ubiquity for identifying where the user is, transparency for being unnoticed, and intelligence for adapting to the preferences of each individual. "The ability to maintain itself," says López Villegas, "is one of the most significant aspects that devices have. For this reason we have to find efficient methodologies, which is to say, materials and systems that can fully take advantage of the available energy and reduce emission/reception unity consumption to a minimum".

To summarize the general future tendencies, technological investigation is moving towards the integration of different technical applications for those habitual environments in which people find themselves. Places such as the home, office, entertainment centers, etc. "will understand" likes and preferences as soon as a user enters. Environmental Intelligence is the new TIC paradigm in which people interact 
within a digital setting that is conscious of human presence, and the given general context of the situation. This intelligence in turn responds to the needs, habits, and emotions of the user.

\subsection{Adaptive and Intelligent Hypermedia Systems}

The first web adaptive and intelligent hypermedia systems (AIHS) date back to the 1990s. During this time, systems began to appear whose origins can be attributed to two interactive multimedia system areas. The first of these was the ITS area - which emphasized extending traditional user models and adaptation approximations with hypermedia components [23-26]. The other was Adaptive Hypermedia Systems (AHS) which attempted to adapt to individual users [27-30]. However, it was only from 1996 that the investigative community began to take interest in this type of system. This is due primarily to two factors: the accumulation and consolidation of investigatory experience in the field and, more importantly, the rapid growth of the World Wide Web. Because of this, there was a demand for systems with a high grade of adaptation to satisfy the variable nature of the intended audiences. So while the majority of the adaptive systems developed before 1996 used classic hypertexts and hypermedia, after 1996 all of the systems were AIHS. Some of the earliest systems were ELM-ART [31], InterBook [32], PT [33], y 2L670 [27]. Pioneer systems which influenced the creation of the posterior systems were: Medtec [34], AST [35], ADI [36], Hy-SOM [37], MetaLinks [38], CHEOPS [39], RATH [40], ACE [41], TANGOW [42], CAMELEON [43], KBS-Hyperbook [44], AHA! [45], SKILL [46], Multibook [47], ART-Web/NetCoach [48] y AHM [49].

Adaptation is one of the principal AIHS characteristics. There are various adaptation technologies that the ITS adopted such as user solution intelligent analysis, presentation adaptation, navigation adaptation, and interactive problem solution support based on examples and other technologies, all of which came from AIHS.

\section{Conclusions}

Recent published social protection and dependency reports emphasize the objective benefits, both physical and emotional, for the elderly - or for those in a situation of dependency or with disabilities - who continue residing in their own home with family assistance. In Spain, currently 8 out of 10 of the elderly or people in a situation of dependency live in their own home. As a consequence, $76 \%$ of families who are faced with this responsibility need some form of aid in order to perform all of the necessary daily tasks. As a further consequence, associations for people with disabilities not only report a lack of adequate aid services, but a lack of direct-family assistance as well. It is necessary, therefore, for an "evolution" or overhaul amongst the social and health service provision systems. The elderly, people in situations of dependency, or people with disabilities should be provided with enough resources and aids to allow them to decide their own future. 
Structural changes in social and health services could provide an increase in the well-being of a country's citizens through the use of self-care programming and proactive management/prevention of disease. Automated home platforms can act as an accessibility instrument which permits users to avoid, compensate, mitigate, or neutralize the deficiencies and dependencies caused by living alone. At the same time it can improve the quality of the user's life by easing domestic device activation and external assistance resource availability. An automated home platform could improve the quality of services given to citizens, as well as optimize resource consumption. At this time, however, automated platforms present some limitations: reduced functionality, insufficient technological infrastructure support, high installation and management cost, lack of privacy, complexity, etc.

Home technologies are becoming more and more orientated towards Environmental Intelligence systems. They consist of a combination of computation technologies and intelligent interfaces which provide an ideal setting for developing adaptive systems. These systems are based on user information and automatically change functionalities and interaction aspects in order to accommodate the preferences and requirements of different people. They can reorganize themselves through independent agents which react according to changes in their environment, or make decisions proactively before those changes occur. This concept has revolutionized the idea of the digital home.

\section{References}

1. Kaptelinin, V.: Activity theory: Implications for human-computer interaction. In: Nardo, B. (ed.). Contexts and consciousness. Activity theory and human-computer interaction, pp. 103--114. The MIT Press: Cambridge (1996)

2. Jones, M.G., Farquhar, J.D., Surry D.W.: Using Metacognitive Theories to Design User Interfaces for Computer-based Learning. Educational Technology, 35, pp. 12--22 (1995)

3. Jones, M.G., Okey, J.R.: Interface Design for Computer-based Learning Environments (1995)

4. Jones, M.G.: Guidelines for screen design and user-interface design in computer-based learning environments. The University of Georgia. Dissertation Abstracts International, 54 (9), pp. 308a--309a (1993)

5. Preece, J., Rogers, Y., Sharp, H., Benyon, D., Holland, S., Carey, T.: $\underline{\text { Human-Computer }}$ Interaction. Wokingham, UK: Addison-Wesley (1994)

6. Thimbleby, H.: User interface design. Chapter 10 (Principles for principles). ACM Press, pp. 197--226 (1990)

7. Preece, J. (ed.): Human-Computer Interaction. New York, NY: Addison-Wesley Publishing (1994)

8. Hackos, J., Redish, J.: User and Task Analysis for Interface Design, Chichester: Wiley (1998)

9. Hartson, H.R.: Advances in Human-Computer Interaction, vol. I. ABLEX Publishing Corporation, New Jersey (1988)

10.Hartson, H.R., Hix, D.: Advances in Human-Computer Interaction, vol. II. ABLEX Publishing Corporation, New Jersey (1988)

11.Hartson, H.R., Hix, D.: Advances in Human-Computer Interaction, vol. III. ABLEX Publishing Corporation, New Jersey (1992) 
12.Carroll, J.M.: Interfacing Thought: Cognitive Aspects of Human-Computer Interaction. Bradford Book. The MIT Press; Cambridge (1989)

13.Nielsen, J.: Usability Engineering. Academic Press, Boston (1993)

14.Alcantud, F.: Nuevas Tecnologías, Viejas Esperanzas. In: VVAA. Nuevas Tecnologías, Viejas Esperanzas: las nuevas tecnologías en el ámbito de la discapacidad y las necesidades educativas especiales. Murcia: Consejería de Educación y Universidades (2000)

15.Dumas, J.S., Redish, J.C.: A practical guide to usability testing. Norwood: Ablex Publishing Corporation (1993)

16.Nielsen, J.: Usability Inspection Methods. In: CHI Tutorials, ACM, pp. $413--414$ (1994)

17.Naveteur, J., Freixa i Baque, E.: Individual differences in electrodermal activity as a function of subjects anxiety, Personality and Individual Differences, 5, pp. 615--626 (1987)

18.Boucsein, W.: Electrodermal activity. New York: Plenum Press (1992)

19.Katkin, E.S.: Electrodermal lability: A Psychophysiological analysis of individual differences in response to stress. In: Sarason J.G. \& Spielberger C.D. (eds.). Stress and Anxiety, Hemisphere Publishing, CO (1975)

20.Spielberger, C.D., Sarason, I.G., Kulcsar, Z.,Van Heck, G.L.(eds).: Stress and Emotion. Series in Stress and Emotion (vol.14): Anxiety, Anger, and Curiosity. Taylor \& Francis. New York: Hemisphere (1991)

21.Sánchez, R.: Tecnologías estimuladoras de las inteligencias (2004). Available at: http://www .aldeaeducativa.com/aldea/articulo.asp?which1=2146

22.Dursteler, J.C.: Sistemas multimodales. Revista digital de InfoVis.net (2004). Available at: http://www.infovis.net/printMag.php?num=139\&lang=1

23.Beaumont, I.: User modeling in the interactive anatomy tutoring system ANATOMTUTOR. User Modeling and User-Adapted Interaction 4(1), pp. 21--46 (1994)

24.Brusilovsky, P., Pesin, L., Zyryanov, M.: Towards an adaptive hypermedia component for an intelligent learning environment. Human-Computer Interaction. Lecture Notes in Computer Science, vol.753, pp 348--358. Springer-Verlag, Berlin (1993)

25.Gonschorek, M., Herzog, C.: Using hypertext for an adaptive helpsystem in an intelligent tutoring system. 7 th World Conference on Artificial Intelligence in Education, Washington, DC, AACE, pp 274--281 (1995)

26.Pérez, T.A., Gutiérrez, J., López, R., González, A., Vadillo, J.A.: Hipermedia, adaptación, constructivismo e instructivismo. Revista Iberoamericana de Inteligencia Artificial, 2, pp. 29--38 (2001)

27.De Bra, P.: Teaching Hypertext and Hypermedia through the Web. Journal of universal computer science, 2(12), pp. 797--804 (1996)

28.De La Passardiere, B., Dufresne A.: Adaptive navigational tools for educational hypermedia. ICCAL'92, 4-th International Conference on Computers and Learning. Berlin. Springer-Verlag, pp. 555--567 (1992)

29.Hohl, H., Böcker, D., Gunzenhäuser, R.: Hypadapter: An adaptive hypertext system for exploratory learning and programming. User Models and User Adapted Interaction, 6 (1996)

30.Kay J., Kummerfeld, R.J.: An individualized course for the C programming language. In: Proceedings of Second International WWW Conference, Chicago, IL, pp. 17--20 (1994)

31.Brusilovsky, P., Schwarz, E., Weber, G.: ELM-ART: An intelligent tutoring system on World Wide Web. In: Frasson, C., Gauthier, G. \& Lesgold, A. (eds.). Intelligent Tutoring Systems. Lecture Notes in Computer Science, vol. 1086, (Proceedings of Third International Conference on Intelligent Tutoring Systems, ITS-96, Montreal, June 12-14, 1996) Berlin, pp. 261--269 (1996)

32.Brusilovsky, P., Schwarz, E., Weber, G.: A tool for developing adaptive electronic textbooks on WWW. In: Maurer, H. (ed.) Proceedings of WebNet'96, World Conference of the Web Society, San Francisco, CA, AACE, Boston, pp. 64--69 (1996) 
33.Kay, J., Kummerfeld, B.: User models for customized hypertext. In: Nicholas, C. \& Mayfield, J. (eds.): Intelligent hypertext: Advanced techniques for the World Wide Web. Lecture Notes in Computer Science, vol. 1326, Berlin: Springer-Verlag (1997)

34.Eliot, C., Neiman, D., Lamar, M.: Medtec: A Web-based intelligent tutor for basic anatomy. In: S. Lobodzinski and I. Tomek (eds.) Proceedings of WebNet'97, World Conference of the WWW, Internet and Intranet, Toronto, Canada, AACE, pp. 161--165 (1997)

35.Specht, M., Weber, G., Heitmeyer, S., Schöch, V.: AST: Adaptive WWWCourseware for Statistics. In: Brusilovsky, P. Fink, J. \& Kay, J. (eds.) Proceedings of Workshop "Adaptive Systems and User Modeling on the World Wide Web", at $6^{\text {th }}$ International Conference on User Modeling, UM97, Chia Laguna, Sardinia, Italy, pp. 91--95 (1997)

36.Schöch, V., Specht, M., Weber, G.: ADI - an empirical evaluation of a tutorial agent. In: T. Ottmann and I. Tomek (eds.) In: Proceedings of ED-MEDIA/ED-TELECOM'98 - 10th World Conference on Educational Multimedia and Hypermedia and World Conference on Educational Telecommunications, Freiburg, Germany, AACE, pp. 1242--1247 (1998)

37.Kayama, M., Okamoto, T.: Hy-SOM: The semantic map framework applied on an example case of navigation. In: G. Cumming, T. Okamoto and L. Gomez (eds.) Advanced Research in Computers and Communications in Education. Frontiers ub Artificial Intelligence and Applications, vol. 2, (Proceedings of ICCE'99, 7th International Conference on Computers in Education, Chiba, Japan, Amsterdam: IOS Press, pp. 252--259 (1999)

38.Murray, T., Condit, C., Haugsjaa, E.: MetaLinks: A preliminary framework for conceptbased adaptive hypermedia. In: Proceedings of Workshop "WWW-Based Tutoring" at 4th International Conference on Intelligent Tutoring Systems (ITS'98), San Antonio, TX (1998)

39.Negro, A., Scarano, V., Simari, R.: User adaptivity on WWW through CHEOPS. In: P. Brusilovsky and P. De Bra (eds.) Proceedings of Second Adaptive Hypertext and Hypermedia Workshop at the Ninth ACM International Hypertext Conference Hypertext'98, Pittsburgh, PA, June 20, 1998 Published as Computing Science Reports, No. 98/12, Eindhoven University of Technology, Eindhoven, pp. 57--62 (1998)

40.Hockemeyer, C., Held, T., Albert, D.: RATH - A relational adaptive tutoring hypertext WWW-environment based on knowledge space theory. In: C. Alvegård (ed.) Proceedings of CALISCE'98, 4th International conference on Computer Aided Learning and Instruction in Science and Engineering, Göteborg, Sweden, pp. 417--423 (1998)

41.Specht, M., Oppermann, R.: ACE - Adaptive Courseware Environment. In: Brusilovsky, P. \& Milosavljevic, M. (eds.). The New Review of Hypermedia and Multimedia 4, Special Issue on Adaptivity and user modeling in hypermedia systems, 141--161 (1998).

42.Carro, R.M., Pulido, E., Rodrígues, P.: TANGOW: Task-based Adaptive learNer Guidance on the WWW. In: Brusilovsky, P. \& De Bra, P. (eds.) Proceedings of Second Workshop on Adaptive Systems and User Modeling on the World Wide Web, Toronto and Banff, Canada, May 11 and June 23-24, 1999 Published as Computer Science Report, No. 99--07, Eindhoven University of Technology, Eindhoven, pp. 49--57 (1999)

43.Laroussi, M., Benahmed, M.: Providing an adaptive learning through the Web case of CAMELEON: Computer Aided MEdium for LEarning on Networks. In: Alvegård, C. (ed.) Proceedings of CALISCE'98, 4th International conference on Computer Aided Learning and Instruction in Science and Engineering, Göteborg, Sweden, pp. 411--416 (1998)

44.Henze, N., Nejdl, W.: Adaptivity in the KBS Hyperbook System. In: Brusilovsky, P., De Bra, P. \& Kobsa, A. (eds.). Proceedings of Second Workshop on Adaptive Systems and User Modeling on the World Wide Web, Toronto and Banff, Canada. Published as Computer Science Report, No. 99-07, Eindhoven University of Technology, Eindhoven, pp. 67--74 (1999)

45.De Bra, P., Calvi, L.: AHA! An open Adaptive Hypermedia Architecture. In: Brusilovsky, P. \& Milosavljevic, M. (eds.). The New Review of Hypermedia and Multimedia 4, Special Issue on Adaptivity and user modeling in hypermedia systems, 115--139 (1998) 
46.Neumann, G., Zirvas, J.: SKILL: A Scalable Internet-Based Teaching and Learning System. In: Maurer, H. \& Olson, R.G. (eds.) Proceedings of WebNet'98, World Conference of the WWW, Internet, and Intranet, Orlando, FL, AACE, pp. 688--693 (1998)

47.Steinacker, A., Seeberg, C., Rechenberger, K., Fischer, S., Steinmetz, R.: Dynamically generated tables of contents as guided tours in adaptive hypermedia systems. In: Proceedings of ED-MEDIA/ED-TELECOM'99 - 11th World Conference on Educational Multimedia and Hypermedia and World Conference on Educational Telecommunications, Seattle, WA, AACE (1999)

48.Weber, G., Kuhl, H.-C., Weibelzahl, S.: Developing adaptive internet based courses with the authoring system NetCoach. In: De Bra, P., Brusilovsky, P. \& Kobsa, A. (eds.) Proceedings of Third workshop on Adaptive Hypertext and Hypermedia, Sonthofen, Germany, Technical University Eindhoven, pp. 35--48 (2001)

49.Pilar da Silva, D., Durm, R.V., Duval, E., Olivié, H.: Concepts and documents for adaptive educational hypermedia: a model and a prototype. In: Brusilovsky, P. \& De Bra, P. (eds.). Proceedings of Second Adaptive Hypertext and Hypermedia Workshop at the Ninth ACM International Hypertext Conference Hypertext'98, Pittsburgh, PA, Published as Computing Science Reports, No. 98/12, Eindhoven University of Technology, Eindhoven. pp. 35--43 (1998) 